\title{
Decreased Esophageal Sensitivity to Acid in Morbidly Obese Patients: A Cause for Concern?
}

\author{
Vicente Ortiz ${ }^{1}$, Diego Alvarez-Sotomayor ${ }^{1}$, Esteban Sáez-González ${ }^{1}$, Francia Carolina Díaz-Jaime ${ }^{1}$, Marisa Iborra $^{1}$, Julio \\ Ponce $^{1}$, and Vicente Garrigues ${ }^{1,2}$ \\ ${ }^{1}$ Digestive Functional Disorders Unit, Gastroenterology Department, La Fe University and Polytechnic Hospital, and ${ }^{2}$ Department of Medicine, \\ University of Valencia, Valencia, Spain
}

See editorial on page 315.

Background/Aims: To evaluate esophageal sensitivity to acid between morbidly obese (MO) patients and non-MO controls with abnormal esophageal acid exposure. Methods: We conducted a cross-sectional study of 58 patients: $30 \mathrm{MO}$ (cases) and 28 non-MO (controls). Esophageal symptoms and esophageal sensitivity to $0.1 \mathrm{M}$ hydrochloric acid solution (Bernstein test) were compared between $\mathrm{MO}$ and nonMO patients with a prior diagnosis of abnormal esophageal acid exposure. Results: MO patients were less symptomatic than non-MO controls (14\% vs 96\%; odds ratio [OR], 0.006; 95\% confidence interval [Cl], 0.001 to $0.075 ; \mathrm{p}=0.000$ ). $\mathrm{MO}$ patients were more likely to present with decreased esophageal sensitivity to the instillation of acid than non-MO controls (57\% vs 14\%; OR, 8; 95\% Cl, 1.79 to 35.74; $p=0.009$ ). Subgroup analysis revealed no differences in esophageal sensitivity in $\mathrm{MO}$ patients with and without abnormal esophageal acid exposure (43\% vs 31\%; $p=0.707$ ). Conclusions: Silent gastroesophageal reflux disease (GERD) is common among MO individuals, likely due to decreased esophageal sensitivity to acid. The absence of typical GERD symptoms in these patients may delay discovery of precancerous conditions, such as Barrett's esophagus. We believe that these patients may require a more aggressive diagnostic work-up to rule out the presence of silent GERD. (Gut Liver 2017;11:358-362)

Key Words: Obesity; Acid reflux; pH monitoring; Gastroesophageal reflux; Sensitivity

\section{INTRODUCTION}

Obesity, defined as a body mass index (BMI) of $\geq 30 \mathrm{~kg} / \mathrm{m}^{2}$, is a common condition in industrialized countries affecting up to $30 \%$ of the total population. The criterion for defining morbid obesity (MO) is a BMI of $\geq 40 \mathrm{~kg} / \mathrm{m}^{2}$, which is estimated to have a prevalence of about a 5\%. The high rates of morbidity and mortality which are associated with obesitiy, ${ }^{2-7}$ alongside its negative impact on health-related quality of life have made it a major public health concern in recent years. ${ }^{8-10}$

Gastroesophageal reflux disease (GERD) is also common in Western countries, and most published epidemiological studies reveal that symptoms are more frequent among the obese population. ${ }^{11-15}$ Furthermore, a study by El-Serag et al. ${ }^{16}$ demonstrated that obesity is an independent risk factor of GERD symptoms and is also related to a higher frequency of esophagitis. In a previous study performed by our group we reported the low sensitivity of heartburn for diagnosing GERD in MO patients, as evidenced by the high proportion of patients who remained asymptomatic despite presenting esophagitis and/or abnormal esophageal acid exposure determined by 24-hour $\mathrm{pH}$ monitoring. ${ }^{17}$ These findings suggest that many MO patients can present lowered esophageal sensitivity to acid and that they may therefore be more likely to suffer silent reflux. Thus, our hypothesis is that GERD is currently underdiagnosed-and consequently, undertreated-in MO patients, a situation which could potentially lead to a higher rate of complications derived from long-term esophageal acid exposure such as reflux esophagitis, Barrett's esophagus and esophageal adenocarcinoma.

Correspondence to: Vicente Ortiz

Digestive Functional Disorders Unit, Gastroenterology Department, La Fe University and Polytechnic Hospital, Avenida Fernando Abril Martorell 106, Valencia 46020, Spain

Tel: +34-670-084404, E-mail: ortiz_vicbel@gva.es

Received on February 12, 2016. Revised on July 7, 2016. Accepted on July 28, 2016. Published online January 20, 2017

pISSN 1976-2283 eISSN 2005-1212 https://doi.org/10.5009/gnl16081

(a) This is an Open Access article distributed under the terms of the Creative Commons Attribution Non-Commercial License (http://creativecommons.org/licenses/by-nc/4.0) which permits unrestricted non-commercial use, distribution, and reproduction in any medium, provided the original work is properly cited. 


\section{MATERIALS AND METHODS}

The primary objective of our study was to compare esophageal sensitivity to the perfusion of $0.1 \mathrm{M}$ hydrochloric acid $(\mathrm{HCl})$ solution in MO and non-MO patients with a prior diagnosis of abnormal esophageal acid exposure.

\section{Study design and patients}

We conducted a cross-sectional study including a total of 58 patients, of which 30 had a BMI $\geq 40 \mathrm{~kg} / \mathrm{m}^{2}$ (cases) and the remaining 28 had a $\mathrm{BMI} \leq 35 \mathrm{~kg} / \mathrm{m}^{2}$ (controls). Patients with MO had been referred for bariatric surgery and were enrolled consecutively from the surgical waiting list. Controls were recruited in a similar fashion during routine outpatient visits to our Functional Gastrointestinal (GI) and Motility Disorders Unit. All patients were required to give their informed consent to participate in the study and fulfil the following inclusion criteria: (1) age $\geq 18$ years; (2) recent upper GI endoscopy; and (3) absence of major comorbid medical conditions. A predefined number of MO patients and all non-MO controls were also required to present objective evidence of abnormal esophageal acid exposure as defined by one or both of the following: (1) presence of esophagitis in upper GI endoscopy or (2) abnormal 24-hour esophageal $\mathrm{pH}$ monitoring results. Of note, patients with heartburn and normal findings in 24-hour $\mathrm{pH}$ monitoring and upper GI endoscopy were not considered to have abnormal esophageal acid exposure. Patient recruitment continued until the target sample size was reached.

After enrollment, patients underwent a structured interview in order to collect all relevant data. Patients were inquired about the presence of digestive symptoms with particular focus on typical GERD symptoms such as heartburn, regurgitation and chest pain. Demographic and anthropometric data as well as information regarding current medication use and toxic habits were also collected. All prior test results and laboratory parameters were obtained from the patient's electronic medical record. Esophageal manometry and 24-hour $\mathrm{pH}$ monitoring were performed in all patients according to a standardized protocol, as described elsewhere. ${ }^{18,19}$

Abnormal espohageal $\mathrm{pH}$ test was defined as $\mathrm{pH}<4$ over a total time of $>4 \%$ (based on our own normality reference values), while presence of esophagitis was determined by upper GI endoscopy and classified according to the Los Angeles classification. ${ }^{20}$ Esophageal sensitivity to acid was evaluated by means of instillation of $0.1 \mathrm{M} \mathrm{HCl}$ solution into the lower esophagus (Bernstein test). This procedure was performed on an empty stomach and on a different day to that of the esophageal manometry and 24-hour $\mathrm{pH}$ test, and all patients were required to discontinue any medications that modify esophageal exposure to acid (e.g., proton pump inhibitors and $\mathrm{H}_{2}$-receptor antagonists) for a minimum period of seven days. The procedure consisted in the introduction of a probe through the nose with the distal orifice positioned $5 \mathrm{~cm}$ above the upper limit of the lower esophageal sphincter, after which a saline solution was instilled through the probe for 20 minutes at a rate of $120 \mathrm{~mL} / \mathrm{hr}$. Immediately afterwards, and without notifying the patient, the perfusion was changed to $0.1 \mathrm{M} \mathrm{HCl}$ solution and maintained at the same rate for a maximum of 30 minutes. The test was considered positive when the perfusion of $\mathrm{HCl}$ triggered the presence of heartburn, provided that it had not been present during the perfusion with saline solution.

\section{Sample size calculation and statistical analysis}

The required sample size was computed by doing power analysis, assuming a positive Bernstein test result in 30\% of MO patients according to our previous data. ${ }^{17}$ Power was set at $80 \%$ to detect an effect size difference of 50\% between groups with and $\alpha$-error level (two-sided) of 0.05. In view of the study's time constraints and foreseeable difficulties in the recruitment of MO patients with abnormal esophageal acid exposure, we decided to use an unbalanced design with a sample size ratio of $2: 1$ between groups. The calculated sample sizes for the MO and nonMO groups were 14 and 28, respectively.

Continuous data are reported as means with the corresponding standard deviations, and Student t-test was used to test for differences in means. Categorical data are presented as absolute values and percentages, and were compared using Fisher exact test. For all implemented tests, a p-value inferior or equal to 0.05 was considered to indicate statistical significance. All calculations were performed with IBM SPSS version 22.0 software (IBM Corp., Armonk, NY, USA).

\section{RESULTS}

Fourteen of the 30 patients in the MO group and all the

Table 1. Demographic, Anthropometric, and Clinical Characteristics of Morbidly Obese and Nonmorbidly Obese Patients with Abnormal Esophageal Acid Exposure

\begin{tabular}{lccc}
\hline & MO $(\mathrm{n}=14)$ & Non-MO (n=28) & p-value* \\
\hline Age, yr & $41.4 \pm 9.7$ & $48.3 \pm 12.0$ & 0.075 \\
Male & $9(64.3)$ & $16(57.1)$ & 0.747 \\
Female & $5(35.7)$ & $12(42.9)$ & 0.747 \\
BMI & $50.5 \pm 7.5$ & $28.3 \pm 4.7$ & 0.000 \\
Weight, kg & $141.7 \pm 18.2$ & $76.2 \pm 14.4$ & 0.000 \\
Height, cm & $168 \pm 7.6$ & $164 \pm 9.1$ & 0.170 \\
Alcohol & $2(14)$ & $6(21.4)$ & 0.308 \\
Smoker & $4(28)$ & $10(36)$ & 0.214 \\
Abnormal 24-hr pH & $11(79)$ & $24(86)$ & 0.668 \\
Esophagitis & $7(50)$ & $20(71)$ & 0.306
\end{tabular}

Data are presented as the mean \pm SD or number $(\%)$.

MO, morbid obesity; BMI, body mass index.

*For continuous data, differences in the means were calculated using Student t-test. Categorical data were analyzed using Fisher exact test. 
patients in the control group presented objective evidence of abnormal esophageal acid exposure. The remaining $16 \mathrm{MO}$ patients had normal findings in these tests. The general characteristics of MO and non-MO patients with abnormal esophageal acid exposure are displayed in Table 1.

Patients with MO were on average 6.9 years older than those without MO, though this difference was no statistically significant $(\mathrm{p}=0.075)$. Similary, MO and non-MO patients did not differ in terms of sex distribution (64.3\% vs 57.1\% males; $\mathrm{p}=0.747$ ), alcohol consumption ( $14 \%$ vs $21.4 \%$; $\mathrm{p}=0.308$ ) or active smoking (28\% vs 36\%; $\mathrm{p}=0.214$ ). Mean BMI was 50.5 in the MO group and 28.3 in the control group ( $\mathrm{p}=0.000)$.

Tables 2 and 3 display the GERD-related characteristics and Bernstein test results of the MO and non-MO groups, respectively. As seen in Table 2, only two patients (14\%) in the MO group complained of regular symptoms such as heartburn, chest pain or regurgitation, and both presented normal esophageal sensitivity to acid (i.e., positive Bernstein test). On the other hand, of the eight patients (57\%) that did exhibit a negative response to the instillation of acid, none complained of any GERD-related symptoms.
Results were rather different in the non-MO controls, as shown in Table 3. The frequency of symptoms in this group was notably higher, with a total of 27 symptomatic subjects (96\%), the majority of which (86\%) also presented a positive Bernstein test. Moreover, the number of individuals with decreased esophageal sensitivity to acid was far lower in this group, with only four (14\%) with a negative Bernstein test result.

Table 4 compares the frequencies of GERD-related symptoms and decreased esophageal sensitivity in both groups. Overall, patients with MO presented a frequency of symptoms which was significantly lower than that of non-MO controls (odds ratio [OR], 0.006; 95\% confidence interval [CI], 0.001 to 0.075 ; $\mathrm{p}=0.000$ ). Similarly, patients with MO were more likely to exhibit a decreased esophageal sensitivity to the instillation of acid when compared to controls without MO (OR, 8; 95\% CI, 1.79 to 35.74; $\mathrm{p}=0.009$ ).

Lastly, we also performed a subgroup analysis and compared the differences in esophageal sensitivity in MO patients with and without abnormal esophageal acid exposure. Results showed no significant differences, with negative Bernstein tests in 43\% and $31 \%$ of patients, respectively ( $\mathrm{p}=0.707$ ).

Table 2. GERD-Related Characteristics and Bernstein Test Results in Morbidly Obese Patients with Abnormal Esophageal Acid Exposure

\begin{tabular}{lccccc}
\hline \multicolumn{1}{c}{ MO (n=14) } & No. (\%) & Symptoms* & Abnormal 24-hr pH & Esophagitis & Negative Bernstein \\
\hline Symptoms & $2(14)$ & - & $2 / 2$ & $1 / 2$ & $0 / 2$ \\
Abnormal 24-hr pH & $11(79)$ & $2 / 11$ & - & $4 / 11$ & $6 / 11$ \\
Esophagitis & $7(50)$ & $1 / 7$ & $4 / 7$ & - & $3 / 7$ \\
Negative Bernstein & $8(57)$ & $0 / 8$ & $6 / 8$ & $3 / 8$ & - \\
\hline
\end{tabular}

Figures in the first column represent absolute numbers and percent of group total, whereas figures in the remaining columns represent within-row fractions.

GERD, gastroesophageal reflux disease; MO, morbid obesity.

*Heartburn, chest pain or regurgitation.

Table 3. GERD-Related Characteristics and Bernstein Test Results in Nonmorbidly Obese Patients with Abnormal Esophageal Acid Exposure

\begin{tabular}{lccccc}
\hline \multicolumn{1}{c}{ Non-MO (n=28) } & No. (\%) & Symptoms* & Abnormal 24-hr pH & Esophagitis & Negative Bernstein \\
\hline Symptoms & $27(96)$ & - & $27 / 27$ & $19 / 27$ & $3 / 27$ \\
Abnormal 24-hr pH & $24(86)$ & $24 / 24$ & - & $16 / 24$ & $3 / 24$ \\
Esophagitis & $20(71)$ & $19 / 20$ & $16 / 20$ & - & $3 / 20$ \\
Negative Bernstein & $4(14)$ & $3 / 4$ & $3 / 4$ & $3 / 4$ & - \\
\hline
\end{tabular}

Figures in the first column represent absolute numbers and percent of group total, whereas figures in the remaining columns represent within-row fractions.

GERD, gastroesophageal reflux disease; MO, morbid obesity.

*Heartburn, chest pain or regurgitation.

Table 4. Differences in Frequency of Symptoms and Esophageal Sensitivity between Morbidly Obese and Nonmorbidly Obese Patients with Abnormal Esophageal Acid Exposure

\begin{tabular}{lccccc}
\hline & MO $(\mathrm{n}=14)$ & Non-MO $(\mathrm{n}=28)$ & OR & 95\% CI & p-value \\
\hline Symptoms $^{*}$ & $2(14)$ & $27(96)$ & 0.006 & $0.001-0.075$ & 0.000 \\
Decreased sensitivity $^{\dagger}$ & $8(57)$ & $4(14)$ & 8 & $1.79-35.74$ & 0.009 \\
\hline
\end{tabular}

Figures in the first two columns represent absolute numbers and percent of group total.

MO, morbid obesity; OR, odds ratio; CI, confidence interval.

*Heartburn, chest pain or regurgitation; ${ }^{\dagger}$ As defined by a negative Bernstein test result. 


\section{DISCUSSION}

Obesity is a prevalent condition in Western countries that is currently reaching epidemic proportions. Similarly, the prevalence of GERD has also been steadily rising in these areas, a situation which has led to increasing interest in the association between these conditions. Several pathophysiologic mechanisms have been proposed to explain the relationship between obesity and gastroesophageal reflux: increased gastric pressure caused by extrinsic compression of surrounding adipose tissue, altered esophageal clearance, anatomical distortion of the esophagogastric junction, hormonal factors such as estrogens and nutritional factors such as a fat-rich diet. ${ }^{21,22}$ In a previous study, we reported that many MO patients present asymptomatic GERD, ${ }^{17}$ and other works have also described an increased frequency of esophageal dysmotility among these asymptomatic patients. ${ }^{23-25}$

The exact mechanisms of visceral symptom manifestation have not yet been fully elucidated, and to this day it is still unclear why patients with MO remain asymptomatic in the presence of esophageal disease. The vagus nerve is known to be involved in the regulation of esophageal sensitivity, a function which seems to be preserved in patients with GERD. ${ }^{26}$ In spite of this, a dysfunction of the autonomic nervous system characterized by a progressive decrease in sympathetic and parasympathetic activity has been observed in MO, which could account for an altered esophageal sensitivity in these patients. ${ }^{27}$ In this sense, the study by Geliebter et al. ${ }^{28}$ demonstrated that obese patients present a lower sensitivity to esophageal balloon distension, while Miwa et al. ${ }^{29}$ investigated the presence of heartburn in 275 patients with confirmed reflux esophagitis and found that $28.5 \%$ of these patients had silent GERD with no typical symptoms. The study by Akyüz et al. ${ }^{30}$ revealed a correlation between acid reflux and BMI in 46 asymptomatic obese individuals. In this group, the frequency of erosive esophagitis was just as high in spite of the absence of symptoms. These data suggest that MO patients may present reduced esophageal perception to noxious stimuli, yet to our knowledge no studies have been published to confirm this by means of objective testing.

Our study has contributed in this respect with several important findings, the first and most relevant of which is the decreased esophageal sensitivity to the instillation of $0.1 \mathrm{M} \mathrm{HCl}$ solution which was observed among subjects in the MO group. This difference was not minor as can be deduced by the eightfold increase in odds ratio; however, it should be noted that the wide confidence intervals indicate that this may not represent an accurate estimate of the true odds ratio found in the general population. In line with this finding was the low frequency of GERD-related symptoms among MO patients (14\%), which was particularly surprising among those with presence of mucosal damage of the esophagus (esophagitis). This was clearly not the case in the non-MO group, where all but one patient (96\%) were symptomatic. As shown in Table 1, these findings were not influenced by an uneven distribution of important covariates such as gender, alcohol consumption and smoking; however, mean age did show clinically relevant (albeit statistically nonsignificant) differences. Fortunately, because the oldest patients belonged to the non-MO group and older age is generally more likely to decrease visceral sensitivity, this age difference will have ultimately had the effect of diminishing our observed differences in esophageal sensitivity, rather than increasing them. Another noteworthy result of our study was the absence of a statistically significant difference in esophageal sensitivity between MO patients with and without abnormal esophageal exposure. This finding suggests that esophageal hyposensitivity may be more related to the presence of MO than GERD, however we should bear in mind that the study was likely to be underpowered for detecting differences in this subgroup analysis.

This research does have a number of limitations that are worth noting. First and most importantly, in spite of the association between MO and decreased sensitivity to acid, the cross-sectional nature of our study did not allow us to establish a causal relationship between the two. This defect is inherent to cross-sectional designs and can only be addressed by means of future prospective studies. An additional limitation concerns the potential use of medications that alter esophageal sensitivity other than proton pump inhibitors and $\mathrm{H}_{2}$-receptor antagonists, such as opiates and other analgesics. The fact that data on these medications were not obtained introduces a potential source of bias; however, given the large effect size difference which was observed between MO and non-MO patients, the overall impact on our final results is likely to have been negligible. Lastly, in order to further explore the mechanisms responsible for the lowered esophageal sensitivity in subjects with MO and to assess the role of GERD, it may have been interesting to include healthy individuals into the study and compare esophageal sensitivity to that of MO patients without abnormal esophageal acid exposure.

In conclusion, our findings are in line with those of other similar studies and clearly indicate that silent GERD is a common condition among MO individuals, and that these individuals also present a decreased esophageal sensitivity to acid. Since patients usually seek medical care as a result of symptom manifestation, the absence of such symptoms is of great clinical relevance because it can potentially delay discovery of precancerous conditions such as Barrett's esophagus, or even esophageal adenocarcinoma. In view of these considerations, we believe that these patients may require a more aggressive diagnostic work-up in order to rule out the presence of silent GERD.

\section{CONFLICTS OF INTEREST}

No potential conflict of interest relevant to this article was reported. 


\section{ACKNOWLEDGEMENTS}

Authorship: Ortiz V, research design and performance, data analysis, manuscript writing; Alvarez-Sotomayor D, data analysis, manuscript writing; Sáez E, data analysis, manuscript writing; Díaz F, data analysis, manuscript writing; Iborra M, research design and performance; Ponce $J$, research design and performance; and Garrigues V, research design and performance, manuscript writing.

\section{REFERENCES}

1. Hedley AA, Ogden CL, Johnson CL, Carroll MD, Curtin LR, Flegal KM. Prevalence of overweight and obesity among US children, adolescents, and adults, 1999-2002. JAMA 2004;291:2847-2850.

2. National Institutes of Health, National Heart, Lung and Blood Institute. Clinical guidelines on the identification, evaluation, and treatment of overweight and obesity in adults: the evidence report. Obes Res 1998;6 Suppl 2:51S-209S.

3. Pi-Sunyer FX. Medical hazards of obesity. Ann Intern Med 1993;119(7 Pt 2):655-660

4. National Task Force on the Prevention and Treatment of Obesity. Overweight, obesity, and health risk. Arch Intern Med 2000;160:898-904.

5. Klein S, Wadden T, Sugerman HJ. AGA technical review on obesity. Gastroenterology 2002;123:882-932.

6. Calle EE, Thun MJ, Petrelli JM, Rodriguez C, Heath CW Jr. Bodymass index and mortality in a prospective cohort of U.S. adults. N Engl J Med 1999;341:1097-1105.

7. Fontaine KR, Redden DT, Wang C, Westfall AO, Allison DB. Years of life lost due to obesity. JAMA 2003;289:187-193.

8. Peeters A, Barendregt JJ, Willekens F, et al. Obesity in adulthood and its consequences for life expectancy: a life-table analysis. Ann Intern Med 2003;138:24-32.

9. Döring N, de Munter J, Rasmussen F. The associations between overweight, weight change and health related quality of life: longitudinal data from the Stockholm public health cohort 20022010. Prev Med 2015;75:12-17.

10. López-García E, Banegas Banegas JR, Gutiérrez-Fisac JL, PérezRegadera AG, Gañán LD, Rodríguez-Artalejo F. Relation between body weight and health-related quality of life among the elderly in Spain. Int J Obes Relat Metab Disord 2003;27:701-709.

11. Dent J, El-Serag HB, Wallander MA, Johansson S. Epidemiology of gastro-oesophageal reflux disease: a systematic review. Gut 2005;54:710-717.

12. Ponce J, Vegazo 0, Beltrán B, et al. Prevalence of gastro-oesophageal reflux disease in Spain and associated factors. Aliment Pharmacol Ther 2006;23:175-184.

13. Murray L, Johnston B, Lane A, et al. Relationship between body mass and gastro-oesophageal reflux symptoms: the Bristol Helicobacter project. Int J Epidemiol 2003;32:645-650.

14. Nilsson M, Johnsen R, Ye W, Hveem K, Lagergren J. Obesity and estrogen as risk factors for gastroesophageal reflux symptoms. JAMA 2003;290:66-72.

15. Rey E, Moreno-Elola-Olaso C, Artalejo FR, Locke GR 3rd, DiazRubio M. Association between weight gain and symptoms of gastroesophageal reflux in the general population. Am J Gastroenterol 2006;101:229-233.

16. El-Serag HB, Graham DY, Satia JA, Rabeneck L. Obesity is an independent risk factor for GERD symptoms and erosive esophagitis. Am J Gastroenterol 2005;100:1243-1250.

17. Ortiz V, Ponce M, Fernández A, et al. Value of heartburn for diagnosing gastroesophageal reflux disease in severely obese patients. Obesity (Silver Spring) 2006;14:696-700.

18. Ponce J, Garrigues V, Pertejo V, Sala T, Berenguer J. Individual prediction of response to pneumatic dilation in patients with achalasia. Dig Dis Sci 1996;41:2135-2141.

19. Garrigues V, Gisbert L, Bastida G, et al. Manifestations of gastroesophageal reflux and response to omeprazole therapy in patients with chronic posterior laryngitis: an evaluation based on clinical practice. Dig Dis Sci 2003;48:2117-2123.

20. Lundell LR, Dent J, Bennett JR, et al. Endoscopic assessment of oesophagitis: clinical and functional correlates and further validation of the Los Angeles classification. Gut 1999;45:172-180.

21. Barak N, Ehrenpreis ED, Harrison JR, Sitrin MD. Gastro-oesophageal reflux disease in obesity: pathophysiological and therapeutic considerations. Obes Rev 2002;3:9-15.

22. El-Serag H. The association between obesity and GERD: a review of the epidemiological evidence. Dig Dis Sci 2008;53:2307-2312.

23. Jaffin BW, Knoepflmacher P, Greenstein R. High prevalence of asymptomatic esophageal motility disorders among morbidly obese patients. Obes Surg 1999;9:390-395.

24. Hong D, Khajanchee YS, Pereira N, Lockhart B, Patterson EJ, Swanstrom LL. Manometric abnormalities and gastroesophageal reflux disease in the morbidly obese. Obes Surg 2004;14:744-749.

25. Suter M, Dorta G, Giusti V, Calmes JM. Gastro-esophageal reflux and esophageal motility disorders in morbidly obese patients. Obes Surg 2004;14:959-966.

26. Hong D, Kamath M, Wang S, Tabet J, Tougas G, Anvari M. Assessment of the afferent vagal nerve in patients with gastroesophageal reflux. Surg Endosc 2002;16:1042-1045.

27. Peterson HR, Rothschild M, Weinberg CR, Fell RD, McLeish KR, Pfeifer MA. Body fat and the activity of the autonomic nervous system. N Engl J Med 1988;318:1077-1083.

28. Geliebter A, Westreich S, Gage D. Gastric distention by balloon and test-meal intake in obese and lean subjects. Am J Clin Nutr 1988;48:592-594.

29. Miwa H, Kondo T, Oshima T, Fukui H, Tomita T, Watari J. Esophageal sensation and esophageal hypersensitivity: overview from bench to bedside. J Neurogastroenterol Motil 2010;16:353-362.

30. Akyüz F, Uyanıkoglu A, Ermis F, et al. Gastroesophageal reflux in asymptomatic obese subjects: an esophageal impedance-pH study. World J Gastroenterol 2015;21:3030-3034. 